\title{
The prevalence and determinants of breast-feeding initiation and duration in a sample of women in Ireland
}

\author{
Roslyn C Tarrant ${ }^{1}$, Katherine M Younger ${ }^{1}$, Margaret Sheridan-Pereira ${ }^{2}$, Martin J White ${ }^{2}$ \\ and John M Kearney ${ }^{1, *}$ \\ ${ }^{1}$ School of Biological Sciences, Dublin Institute of Technology, Kevin Street, Dublin 8, Republic of Ireland: \\ ${ }^{2}$ Department of Paediatrics, The Coombe Women and Infants University Hospital, Dublin 8, Republic of Ireland
}

Submitted 4 March 2009: Accepted 6 August 2009: First published online 17 September 2009

\begin{abstract}
Objective: To assess breast-feeding initiation and prevalence from birth to 6 months in a sample of mothers in Dublin, and to determine the factors associated with breast-feeding initiation and 'any' breast-feeding at 6 weeks in a sample of Irish-national mothers.

Design: This prospective cross-sectional study involved the recruitment of women during the antenatal period, with subsequent follow-up of mothers who delivered healthy, term singleton infants, at 6 weeks and 6 months postpartum.

Setting: Participants were recruited from antenatal clinics in the Coombe Women and Infants University Hospital, Dublin.

Subjects: In all, 401 Irish-national and forty-nine non-Irish-national mothers met the criteria for inclusion in the present study.

Results: Breast-feeding initiation rates of the Irish-national and non-Irish-nationals were $47 \%$ and $79 \cdot 6 \%$, respectively. Factors that were significantly $(P=0 \cdot 000)$ associated with both breast-feeding initiation and 'any' breast-feeding at 6 weeks included mothers who were $\geq 35$ years, educated to third level, reported positive postnatal encouragement to breast-feed from their partners and had a positive antenatal intention to breast-feed. The maternal negative perception that breastfeeding is an embarrassing way to feed an infant was demonstrated as a major barrier to initiation.

Conclusions: Breast-feeding initiation and prevalence rates of the Irish-national population remain low and lag considerably behind national and international targets. Inclusion of the partner in breast-feeding promotional initiatives during the antenatal period may be crucial to increase breast-feeding rates in Ireland. Public health campaigns that focus on increasing the social acceptability of breastfeeding may prove effective in addressing this cultural barrier.
\end{abstract}

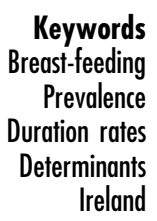

The evidence for the short- and long-term health benefits of breast-feeding for the young infant ${ }^{(1,2)}$ and mother ${ }^{(3,4)}$, in both developing ${ }^{(5,6)}$ and developed countries ${ }^{(7-9)}$, is robust, and recognised globally ${ }^{(10,11)}$. More recently, data suggest that the promotion of exclusive breast-feeding for prolonged duration ${ }^{(12,13)}$ may represent a potentially ideal window of opportunity for obesity prevention ${ }^{(14-16)}$, which is especially pertinent as childhood and adulthood obesity rates are increasing both in Ireland ${ }^{(17,18)}$ and internationally ${ }^{(19,20)}$. The WHO globally recommends exclusive breast-feeding during the first 6 months of life with the introduction of solid foods thereafter, and continued breast-feeding until 2 years of age or above ${ }^{(21)}$, a recommendation that was subsequently endorsed in Ireland in $2003^{(22)}$. Although the rates of exclusive breastfeeding at 6 months postpartum are low internationally ${ }^{(23)}$, it is well documented that the breast-feeding rates in Ireland throughout infancy are among the lowest worldwide ${ }^{(24-27)}$.

Recent figures from the 2005 National Perinatal Statistics (NPS) report an initiation rate (rate of exclusive breast-feeding upon hospital discharge or under domiciliary care) of $44 \%{ }^{(28)}$, a rate well below Irish and international targets. This figure represents only a small increase in breast-feeding initiation from previous NPS $^{(28)}$, including $42.5 \%$ in 2004, $41 \%$ in both 2003 and 2002 and 39\% in 2001, in comparison to higher breastfeeding initiation rates reported internationally in 2005 , including $78 \%$ in the Netherlands $(n 9133)^{(29)}, 71 \%$ in the USA $(n 3444)^{(30)}$ and $71 \%$ in the UK $(n 18125)^{(31)}$.

To improve breast-feeding rates, it is emphasised that ascertaining the factors important to a mother's decision about how to feed her infant is crucial ${ }^{(32)}$. Moreover, the acquisition of country-specific knowledge about the type 
and importance of the determinants for breast-feeding is essential for building effective promotion programmes ${ }^{(33)}$. However, a paucity of data exists with regard to the feeding of infants in Ireland ${ }^{(34)}$, and greater investigations are needed to explain the persistently low breast-feeding rates $^{(35)}$. Difficulties are compounded by the fact that no national breast-feeding monitoring system exists beyond the point of hospital discharge in Ireland, resulting in a total lack of national breast-feeding duration rates. Furthermore, no published data are currently available on the feeding of infants born to non-Irish-national mothers, a population which now accounts for $10 \%$ of the current population in Ireland ${ }^{(36)}$. Although several regional studies have been carried out to examine breast-feeding rates ${ }^{(37,38)}$, some of these studies ${ }^{(39-41)}$ do not include well-defined breastfeeding definitions, making comparison with other national and international breast-feeding data difficult ${ }^{(42)}$. Further limitations in Irish-based infant-feeding studies relate to the reported recruitment bias towards mothers from higher socio-economic groups ${ }^{(43,44)}$ and the exclusion of asylum seekers, because of the difficulties in the follow-up of this population $^{(38)}$.

In view of the above, we undertook the present study to assess breast-feeding initiation and prevalence from birth to 6 months in a sample of mothers in Dublin, and to determine the factors associated with breast-feeding initiation and 'any' breast-feeding at 6 weeks in a sample of Irish-national mothers.

\section{Experimental methods}

\section{Study design and population}

This cross-sectional, prospective study (1 June 2004-31 October 2006) involved the recruitment of 491 pregnant women from separate public, semi-private and private antenatal clinics in the Coombe Women and Infants University Hospital (CWIUH) in west Dublin. During the study interval, the CWIUH had membership to the Breast-feeding Friendly Hospital Initiative.

Specific and separate weekly timetabled public, semiprivate and private antenatal clinics are held in the CWIUH. Across the seating arrangements in each clinic women were consecutively invited to participate in the present study. Women were deemed eligible to participate if they were $\geq 24$ weeks gestational age, reported a singleton pregnancy and were planning to reside in Ireland for at least 6 months postpartum. Representing the sociodemographic profile of women who attend public and semi-private/private antenatal clinics (58\% and $42 \%$, respectively) in the hospital, $51 \%$ and $49 \%$ of the study cohort were recruited from these clinics, respectively.

From the initial sample of 539 women who met the study inclusion criteria, and who were invited to participate in the present study, 491 women (91\%) agreed to participate and gave signed consent.
All eligible mothers who subsequently delivered a healthy, singleton, term infant $\geq 37$ weeks gestational age, weighing $\geq 2.5 \mathrm{~kg}$ at birth, were followed up postpartum. Follow-up of mothers consisted of either a telephone or a face-to-face interview by one investigator within a time frame of $7 \mathrm{~d}$ after the infants 6 th week and at 6 months of age. Of the 491 mothers who were recruited, 98\% ( $n$ 483) were followed up at the 6-week follow-up and from this sample, $94 \%$ of mothers ( $n$ 454) were followed up at 6 months. Owing to case exclusions due to missing values ( $n$ 4), infant prematurity ( $n$ 19), one postnatal infant death and five intra-uterine deaths, as well as cases lost to followup ( $n$ 12), 450 mothers met the criteria for the final data analysis. This final sample included 401 Irish-national, 49 non-Irish-national mothers.

\section{Data collection}

Data were collected using three semi-structured questionnaires. The first questionnaire was completed by mothers at recruitment in the hospital antenatal clinic, with a follow-up interviewer-administered questionnaire at 6 weeks and 6 months postpartum, either in the hospital clinic, in the mothers' home or via telephone. Questions addressed breast-feeding initiation and duration ${ }^{(45)}$, maternal perceptions and attitudes ${ }^{(46)}$, ethnic considerations ${ }^{(47)}$, factors related to the partner ${ }^{(10)}$ and mother's employment status $^{(48,49)}$. All three questionnaires were pre-tested on three separate pilot groups.

The first self-administered questionnaire was designed to record information on variables suggested to be associated with infant-feeding decisions including mothers': infant-feeding history, attitudes/exposure to breastfeeding and perception of partners' infant-feeding preference. Maternal and paternal reported sociodemographic, anthropometric and employment factors were also identified. Data relating to mothers medical and obstetric status were obtained from the medical notes.

The 6-week and 6-month interviewer-administered questionnaires aimed to collect quantitative data on mothers' infant-feeding methods and practices along with the reasons for such feeding choices. Data relating to inhospital practices including rooming-in, occurrence of skinto-skin contact and mothers' satisfaction with the support received on the ward, post birth, were elicited from the 6-week questionnaire. Detailed barriers to breast-feeding initiation or reasons for early discontinuation were elicited in both follow-up questionnaires. Mothers were questioned on their infant's milk-feeding status and/or the inclusion of solid foods in their infant's diet. Infant-feeding status was collected at a moment in time via maternal $24 \mathrm{~h}$ recall of the infant's usual diet at 6 weeks and again, at 6 months. Any feeding transitions that occurred between the contact points with mothers were retrospectively recorded, enabling the collection of infant-feeding status at the point of hospital discharge, at 4, 8, 12, 16 and 20 weeks postpartum. For mothers who initiated breast-feeding but who 
were no longer breast-feeding at 6 weeks or 6 months, data were collected on the number of days the mothers exclusively, predominantly or partially breast-fed, from which the duration of 'any' breast-feeding was recorded.

The definitions of exclusive and predominant breastfeeding in the present study were in accordance with the $\mathrm{WHO}^{(50,51)}$ breast-feeding definitions and were strictly used. Thus, exclusive breast-feeding referred to mothers who only offered breast milk to their infants (including expressed breast milk), while giving no other food or liquid, not even water, with the exception of drops or syrups (vitamins, minerals, medicines). 'Partial breast-feeding' included infants who received breast milk in combination with formula feeds or other non-human milk feeds and/or solid food ${ }^{(52,53)}$ and 'any' breast-feeding referred to all infants who received 'any' breast milk or a combination of breast milk with other nonhuman milk feeds and/or solid food ${ }^{(30,54)}$. Breast-feeding 'initiation' in the present study was defined as all mothers who 'ever' tried to breast-feed post birth.

\section{Statistical analyses}

The Statistical Package for the Social Sciences statistical software package version 13.0 (SPSS Inc.; Chicago, IL, USA) was used for all statistical analyses. Comparison between groups was performed by means of the Student's $t$ test for continuous variables and by the $\chi^{2}$ test for categorical variables using the Yates's continuity correction value when two dichotomous variables were analysed. Data are presented using numerical descriptive statistics, including means with standard deviations (SD) and medians with interquartile ranges (IQ). Descriptive statistics and crosstabulations were generated for demographic factors, tables were used for breast-feeding rates and binary logistic regression was used to predict breast-feeding initiation and 'any' breast-feeding at 6 weeks.

To explore the independent factors associated with breast-feeding initiation and 'any' breast-feeding at 6 weeks, only those factors that were significant $(P<0.05)$ in univariate analysis were included in binary logistic regression models. Univariate and adjusted odds ratios (OR) and 95\% confidence intervals (CI) were calculated for each factor.

\section{Ethical considerations}

Ethical approval for the present study was obtained from the ethics committee of the CWIUH and the Dublin Institute of Technology. Informed consent was obtained from the parent(s).

\section{Results}

\section{Sociodemographic, biomedical and infant characteristics of the sample}

Table 1 shows the social and demographic characteristics of the Irish-national and non-Irish-national mothers for whom complete data are available from the 6-week (mean 6.56 weeks (SD 0•42)) and 6-month (mean $24 \cdot 7$ weeks (SD 0•43)) follow-up. The two populations differed in terms of marital status $(P=0 \cdot 042)$ and maternal social class $(P=0 \cdot 003)$, with a higher proportion of married and stay-at-home mothers observed in the non-Irish-national population. In addition, a shorter duration of hospital stay $(P=0 \cdot 05)$ was observed in the non-Irish-national, compared to the Irish-national population $(3.2 \mathrm{~d}$ ( $\mathrm{SD} 1.63)$ v. $3.7 \mathrm{~d}$ (SD 1.75$)$, respectively).

The non-responders in the present study ( $n$ 48) were either unwilling to take part or were planning to emigrate from Ireland during the initial months postpartum. Compared to the responders, the non-responders were significantly $(P=0 \cdot 001)$ more likely to be younger, smokers and reported an antenatal intention to formulafeed postpartum (data not shown).

\section{Breast-feeding initiation and prevalence}

In total, $47 \%$ ( $n$ 189) of the Irish-national and 79.6\% ( $n$ 39) of the non-Irish-national mothers initiated breastfeeding postpartum $(P=0 \cdot 000)$. Significantly higher 'any', exclusive and partial breast-feeding rates were observed in the non-Irish-national compared to the Irish-national population $(P=0 \cdot 000)$ during the first 20 weeks (see Table 2). The highest drop in 'any' breast-feeding was observed between hospital discharge and 4 weeks in the Irish-national mothers $(10 \cdot 3 \%)$ and between 4 and 6 weeks in the non-Irish-national mothers $(8 \cdot 2 \%)$. Less than half $(44 \%)$ of the Irish-national mothers who initiated breast-feeding were exclusively breast-feeding at 4 weeks postpartum and from the two populations, only one Irishnational mother was still exclusively breast-feeding at 6 months. While the partial breast-feeding rate of the Irish-national mothers remained relatively unchanged during the first 6 months $(6 \cdot 5-9 \cdot 4 \%)$, there was a marked trend towards increased partial breast-feeding between 12 weeks and 6 months in the non-Irish-national population.

\section{Breast-feeding duration rates}

The duration of 'any' breast-feeding during the study time frame was significantly higher $(P=0 \cdot 000)$ in the nonIrish-national (median $170 \mathrm{~d}$, IQ 84-175) compared to the Irish-national (median $56 \mathrm{~d}$, IQ 7-126) population. No significant difference $(P=0.510)$ was observed in the number of days mothers exclusively breast-fed between the two populations (median $56 \mathrm{~d}$, IQ 0-112 v. median 21 d, IQ 2-84, respectively).

\section{Determinants of breast-feeding initiation in the Irish-national population}

The sociodemographic factors that influenced breast-feeding initiation after adjustment included: non-smoking (OR $3 \cdot 1 ; 95 \%$ CI $1 \cdot 6,5 \cdot 9)$ primiparous (OR $3 \cdot 1 ; 95 \%$ CI $1 \cdot 9,5 \cdot 2$ ) mothers, $\geq 35$ years (OR 5.4; $95 \%$ CI $2 \cdot 4,12 \cdot 4$ ) and educated to third level education (OR $4 \cdot 1 ; 95 \%$ CI $2 \cdot 3,7 \cdot 4$ ) (see Table 3). Almost $94 \%$ of the mothers who initiated breast-feeding reported a positive antenatal intention to 
Table 1 Social and demographic characteristics of the Irish-national and non-Irish-national mothers as well as the characteristics of their infants

\begin{tabular}{|c|c|c|c|c|}
\hline \multirow[b]{2}{*}{ Characteristic } & \multicolumn{2}{|c|}{ Irish-national mothers ( $n$ 401) } & \multicolumn{2}{|c|}{ Non-Irish-national mothers $(n 49)$} \\
\hline & $\%$ & $n$ & $\%$ & $n$ \\
\hline \multicolumn{5}{|l|}{ Maternal education } \\
\hline Primary and secondary & $39 \cdot 9$ & 160 & $34 \cdot 7$ & 17 \\
\hline Vocational/training course & $28 \cdot 7$ & 115 & $18 \cdot 4$ & 9 \\
\hline Third level degree/postgraduate level & $31 \cdot 4$ & 126 & $46 \cdot 9$ & 23 \\
\hline \multicolumn{5}{|l|}{ Maternal age (years) } \\
\hline$\leq 24$ & $22 \cdot 4$ & 90 & $16 \cdot 3$ & 8 \\
\hline 25-34 & $59 \cdot 4$ & 238 & $59 \cdot 2$ & 29 \\
\hline$\geq 35$ & $18 \cdot 2$ & 73 & $24 \cdot 5$ & 12 \\
\hline \multicolumn{5}{|l|}{ Marital status* } \\
\hline Married & $58 \cdot 6$ & 235 & $75 \cdot 5$ & 37 \\
\hline Unmarried/partnered & $30 \cdot 9$ & 124 & $22 \cdot 4$ & 11 \\
\hline Single & $10 \cdot 5$ & 42 & $2 \cdot 0$ & 1 \\
\hline \multicolumn{5}{|l|}{ Maternal social class ${ }^{\star \star}$ (based on occupationt) } \\
\hline Social class 1 & $30 \cdot 9$ & 124 & $32 \cdot 7$ & 16 \\
\hline Social class 2 & $30 \cdot 7$ & 123 & $10 \cdot 2$ & 5 \\
\hline Social class 3 & $11 \cdot 5$ & 46 & $6 \cdot 1$ & 3 \\
\hline Unknown category (unemployed/students) & $11 \cdot 5$ & 46 & $22 \cdot 4$ & 11 \\
\hline Stay-at-home mothers/home-makers & $15 \cdot 5$ & 62 & $28 \cdot 6$ & 14 \\
\hline \multicolumn{5}{|l|}{ Employment status of mothers postpartum } \\
\hline Returned to work $\leq 18$ weeks & $19 \cdot 7$ & 79 & $10 \cdot 2$ & 5 \\
\hline Returned to work $>18$ weeks & $18 \cdot 2$ & 73 & $10 \cdot 2$ & 5 \\
\hline Did not return to work outside the home & $62 \cdot 1$ & 249 & $79 \cdot 6$ & 39 \\
\hline \multicolumn{5}{|l|}{ Parity } \\
\hline Primiparous & $48 \cdot 9$ & 196 & $34 \cdot 7$ & 17 \\
\hline Multiparous & $51 \cdot 1$ & 205 & $65 \cdot 3$ & 32 \\
\hline \multicolumn{5}{|l|}{ Gender of infant } \\
\hline Male & $55 \cdot 6$ & 223 & $55 \cdot 1$ & 27 \\
\hline Female & $44 \cdot 4$ & 178 & $44 \cdot 9$ & 22 \\
\hline \multicolumn{5}{|l|}{ Type of delivery } \\
\hline Spontaneous vaginal delivery & $76 \cdot 6$ & 307 & $75 \cdot 5$ & 37 \\
\hline Caesarean section & $23 \cdot 4$ & 94 & $24 \cdot 5$ & 12 \\
\hline \multicolumn{5}{|l|}{ Birth weight $(\mathrm{kg})$} \\
\hline$\leq 2.99$ & $14 \cdot 5$ & 58 & $14 \cdot 3$ & 7 \\
\hline $3-4$ & $69 \cdot 1$ & 277 & $65 \cdot 3$ & 32 \\
\hline \multirow[t]{2}{*}{$>4$} & $16 \cdot 5$ & 66 & $20 \cdot 4$ & 10 \\
\hline & Mean & SD & Mean & SD \\
\hline Gestational age at birth (weeks) & $40 \cdot 21$ & $1 \cdot 3$ & $39 \cdot 86$ & $1 \cdot 14$ \\
\hline
\end{tabular}

${ }^{*} P=0.042 ;{ }^{*} P=0.003$

+Maternal occupations were categorised according to the social class categories from the UK ${ }^{(55)}$ and Irish ${ }^{(56)}$ classification system; a separate category was created for those who reported that they were 'stay-at-home mothers'.

breast-feed postpartum compared to $94 \%$ of the noninitiators who had no positive antenatal intention to breastfeed. After adjustment, mothers' positive antenatal feeding intention to breast-feed was indicated as one of the most important independent determinants $(P=0 \cdot 000)$ of breast-feeding initiation (OR 224; 95\% CI 85, 587). Mothers who reported positive postnatal encouragement to breast-feed from the partner (OR $7 \cdot 9 ; 95 \%$ CI $4 \cdot 6,13 \cdot 8$ ) and the maternal grandmother (OR 6.2; $95 \%$ CI 3·4, 11.3) were significantly more likely to initiate breast-feeding. Maternal antenatal attitudes towards breast-feeding were also found to influence a mothers' feeding decision with those who reported that breast-feeding is 'not embarrassing' being significantly more likely to initiate the practice.

\section{Maternal perceptions about breast-feeding initiation}

The principal perceived reasons reported by mothers for initiating breast-feeding related to the optimum health benefits of breast milk (54\%), intrinsic mother-led reasons such as a wish to promote bonding and maternal instinct (18\%) along with positive encouragement from others (health professionals, family, friends) to breast-feed $(15 \%)$ (data not shown). The following were the principal perceived reasons reported by mothers for not initiating breast-feeding: embarrassment of breast-feeding in front of others/in public (31\%), time and lifestyle restrictions associated with breast-feeding (24\%), a reported negative perception of breast-feeding (11\%), as well as mothers' general preference not to breast-feed ( $8 \%$ ) (data not shown).

\section{Determinants of 'any' breast-feeding at 6 weeks in the Irish-national population}

As presented in Table 4, the factors that influenced 'any' breast-feeding at 6 weeks included primiparous (OR 1.9; $95 \%$ CI $1,3 \cdot 4$ ) mothers, $\geq 35$ years (OR 4.9; $95 \%$ CI $1 \cdot 6$, $14 \cdot 4$ ) and educated to third level (OR 5·7; $95 \%$ CI $2 \cdot 7,12 \cdot 2$ ). Similar to the factors influencing initiation, mothers who had 


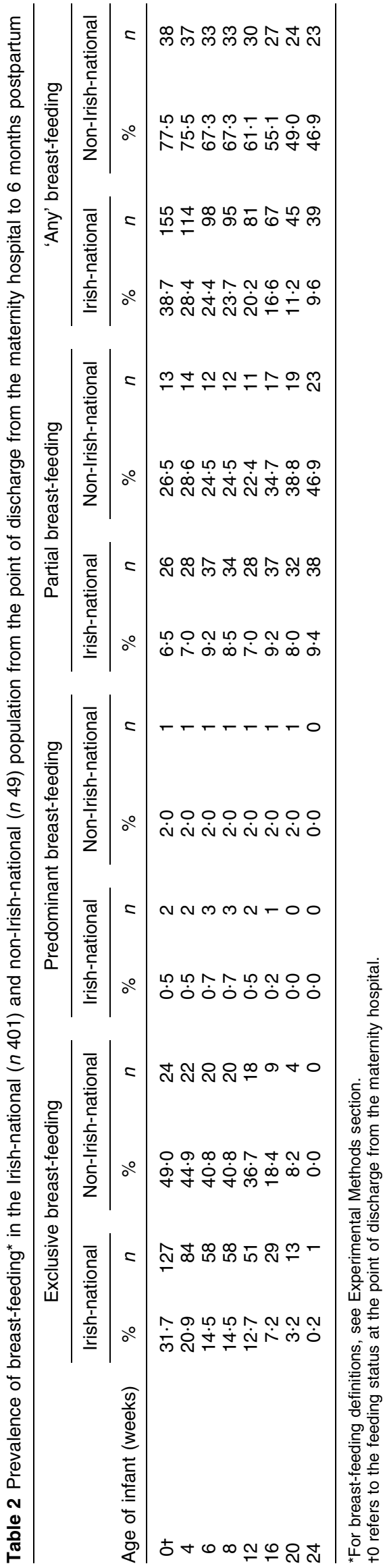

positive antenatal feeding intention to breastfeed (OR 31.7; $95 \%$ CI $10.5,95)$, reported positive encouragement to breast-feed from the partner (OR 4•0; $95 \%$ CI 2.2, 7·3) and who had the perception that breast-feeding is 'natural' (OR 3.7; $95 \%$ CI 2, 6.8) were more likely to have been offering 'any' breast milk to their infants at 6 weeks.

\section{Reasons for discontinuing breast-feeding during the first 6 weeks}

The principal reasons for discontinuing breast-feeding during the first 6 weeks postpartum related to maternal tiredness (26\%) as well as to the demands of breastfeeding due to frequent feeding frequency (23\%). Almost one-sixth of mothers $(17 \%)$ discontinued owing to their perception that they had an inadequate breast milk supply and the perception that the breast milk was not satisfying their infant's hunger. Few mothers reported work return (1\%), lack of breast-feeding support and reassurance (1\%), and infant- (4\%) and mother-related illness $(5 \%)$ as the principal reasons for abandoning the practice (data not shown).

\section{Discussion}

Despite the recognised benefits of breast-feeding ${ }^{(1-9)}$, the majority of infants born in Ireland never experience the benefits of breast milk ${ }^{(28)}$, a pattern that has been observed over the last 30 years ${ }^{(57-59)}$. With a view to increasing breastfeeding rates, the present study sought to provide data on breast-feeding initiation and prevalence in a sample of Irish-national and non-Irish-national mothers, including the factors that influence initiation and 'any' breast-feeding at 6 weeks in the former population.

An important finding from the present study was the significant difference in the breast-feeding initiation and prevalence rates between the two study populations. While the high breast-feeding initiation rate of the nonIrish-national population $(79 \cdot 6 \%)$ in the present study is comparable with initiation rates (71-84\%) reported internationally ${ }^{(30,60,61)}$, the initiation rate of $47 \%$ found in the Irish-national population remains low and far from the achievement of national breast-feeding targets ${ }^{(24)}$. In contrast, lower initiation rates of $39.5 \%, 38 \%$ and $36 \%$ have been reported in earlier studies from Dublin ${ }^{(62)}$, Co. Kildare $^{(39)}$ and Galway ${ }^{(63)}$, respectively; however, more recent regional studies from Dublin ${ }^{(38,59)}$ report a higher initiation rate of $51 \%$.

Interestingly, the $2004 \mathrm{NPS}^{(28)}$, which coincided with the first year of data collection in the present study, reports that $42.5 \%$ of mothers in Ireland were exclusively breast-feeding at hospital discharge, which is over $10 \%$ higher than the figure found here among Irishnational mothers $(31 \cdot 7 \%)$. It is thus possible that the low breast-feeding rates found in the present study were specific to the mothers who attended the CWIUH 
Table 3 Factors influencing breast-feeding initiation in the Irish-national population, performed by binary logistic regression analysis

\begin{tabular}{|c|c|c|c|c|c|c|c|c|c|}
\hline \multirow[b]{2}{*}{ Factors } & \multicolumn{2}{|c|}{ Initiated $(n$ 189) } & \multicolumn{2}{|c|}{ Non-initiators ( $n$ 212) } & \multicolumn{2}{|c|}{ Univariate } & \multicolumn{2}{|c|}{ Adjusted* $^{*}$} & \multirow[b]{2}{*}{$P$ value } \\
\hline & $\%$ & $n$ & $\%$ & $n$ & OR & $95 \% \mathrm{Cl}$ & OR & $95 \% \mathrm{Cl}$ & \\
\hline \multicolumn{10}{|l|}{ Maternal education } \\
\hline Primary and secondary & $23 \cdot 3$ & 44 & $54 \cdot 7$ & 116 & $1 \cdot 0+$ & & $1 \cdot 0$ & & \\
\hline Vocational/training course & $30 \cdot 2$ & 57 & $27 \cdot 4$ & 58 & $2 \cdot 5$ & $1 \cdot 5,4 \cdot 2$ & $2 \cdot 3$ & $1 \cdot 3,4 \cdot 1$ & \\
\hline Third level degree/postgraduate level & $46 \cdot 6$ & 88 & $17 \cdot 9$ & 38 & $6 \cdot 1$ & $3 \cdot 6,10 \cdot 2$ & $4 \cdot 1$ & $2 \cdot 3,7 \cdot 4$ & 0.000 \\
\hline \multicolumn{10}{|l|}{ Maternal age (years) } \\
\hline$\leq 24$ & $13 \cdot 8$ & 26 & $30 \cdot 2$ & 64 & $1 \cdot 0$ & & $1 \cdot 0$ & & \\
\hline $25-34$ & $59 \cdot 8$ & 113 & $59 \cdot 0$ & 125 & $2 \cdot 2$ & $1 \cdot 3,3 \cdot 7$ & $1 \cdot 5$ & $0 \cdot 8,2 \cdot 9$ & \\
\hline$\geq 35$ & $26 \cdot 5$ & 50 & $10 \cdot 8$ & 23 & $5 \cdot 3$ & $2 \cdot 7,10 \cdot 4$ & $5 \cdot 4$ & $2 \cdot 4,12 \cdot 4$ & 0.000 \\
\hline \multicolumn{10}{|l|}{ Smoking status during pregnancy } \\
\hline Yes & $8 \cdot 5$ & 16 & $36 \cdot 3$ & 77 & $1 \cdot 0$ & & $1 \cdot 0$ & & \\
\hline No & $91 \cdot 5$ & 173 & $63 \cdot 7$ & 135 & $6 \cdot 1$ & $3 \cdot 4,11$ & $3 \cdot 1$ & $1 \cdot 6,5 \cdot 9$ & 0.001 \\
\hline \multicolumn{10}{|l|}{ Parity } \\
\hline Multiparous & $40 \cdot 7$ & 77 & $60 \cdot 4$ & 128 & $1 \cdot 0$ & & $1 \cdot 0$ & & \\
\hline Primiparous & $59 \cdot 3$ & 112 & $39 \cdot 6$ & 84 & $2 \cdot 2$ & $1 \cdot 4,3 \cdot 3$ & $3 \cdot 1$ & $1 \cdot 9,5 \cdot 2$ & 0.000 \\
\hline \multicolumn{10}{|l|}{ Type of delivery } \\
\hline Spontaneous vaginal delivery & $75 \cdot 7$ & 143 & $77 \cdot 4$ & 164 & $1 \cdot 0$ & & $1 \cdot 0$ & & \\
\hline Caesarean section & $24 \cdot 3$ & 46 & $22 \cdot 6$ & 48 & $1 \cdot 0$ & $0 \cdot 6,1 \cdot 7$ & $0 \cdot 7$ & $0 \cdot 4,1 \cdot 2$ & $0 \cdot 227$ \\
\hline \multicolumn{10}{|l|}{ Gender of infant } \\
\hline Female & $41 \cdot 3$ & 78 & $47 \cdot 2$ & 100 & $1 \cdot 0$ & & $1 \cdot 0$ & & \\
\hline Male & $58 \cdot 7$ & 111 & $52 \cdot 8$ & 112 & $1 \cdot 2$ & $0 \cdot 8,1 \cdot 8$ & $1 \cdot 2$ & $0 \cdot 7,1 \cdot 9$ & 0.391 \\
\hline \multicolumn{10}{|l|}{ Birth weight $(\mathrm{kg})$} \\
\hline$\leq 2.99$ & $7 \cdot 4$ & 14 & $20 \cdot 8$ & 44 & $1 \cdot 0$ & & $1 \cdot 0$ & & \\
\hline $3-4$ & $72 \cdot 0$ & 136 & $66 \cdot 5$ & 141 & $3 \cdot 0$ & $1 \cdot 5,5 \cdot 7$ & $2 \cdot 1$ & $1 \cdot 0,4 \cdot 4$ & \\
\hline$>4$ & $20 \cdot 6$ & 39 & $12 \cdot 7$ & 27 & $4 \cdot 5$ & $2 \cdot 0,9 \cdot 8$ & $2 \cdot 3$ & $0 \cdot 9,5 \cdot 5$ & $0 \cdot 111$ \\
\hline \multicolumn{10}{|l|}{ Mothers' antenatal infant-feeding intention } \\
\hline No positive intention to breast-feed & $6 \cdot 3$ & 12 & 93.9 & 199 & $1 \cdot 0$ & & $1 \cdot 0$ & & \\
\hline Positive intention to breast-feed & $93 \cdot 7$ & 177 & $6 \cdot 1$ & 13 & $225 \cdot 7$ & 100,507 & 224 & 85,587 & 0.000 \\
\hline \multicolumn{10}{|c|}{ Mothers' antenatal attitude to breast-feeding practice being } \\
\hline Embarrassing & $37 \cdot 6$ & 71 & $59 \cdot 9$ & 127 & $1 \cdot 0$ & & $1 \cdot 0$ & & \\
\hline Not embarrassing & $62 \cdot 4$ & 118 & $40 \cdot 1$ & 85 & $2 \cdot 4$ & $1 \cdot 6,3 \cdot 7$ & $2 \cdot 3$ & $1 \cdot 4,3 \cdot 7$ & 0.000 \\
\hline \multicolumn{10}{|l|}{ Feeding mode encouraged by the partner postnatally $\neq$} \\
\hline Did not encourage breast-feeding & $33 \cdot 2$ & 61 & $80 \cdot 5$ & 149 & $1 \cdot 0$ & & $1 \cdot 0$ & & \\
\hline Positively encouraged breast-feeding & $66 \cdot 8$ & 123 & $19 \cdot 5$ & 36 & $8 \cdot 3$ & $5 \cdot 1,13 \cdot 4$ & $7 \cdot 9$ & $4 \cdot 6,13 \cdot 8$ & 0.000 \\
\hline \multicolumn{10}{|c|}{ Feeding mode encouraged by the maternal grandmother } \\
\hline Did not encourage breast-feeding & $59 \cdot 3$ & 112 & $87 \cdot 3$ & 185 & $1 \cdot 0$ & & $1 \cdot 0$ & & \\
\hline Positively encouraged breast-feeding & $40 \cdot 7$ & 77 & $12 \cdot 7$ & 27 & $4 \cdot 7$ & $2 \cdot 8,7 \cdot 7$ & $6 \cdot 2$ & $3 \cdot 4,11 \cdot 3$ & 0.000 \\
\hline \multicolumn{10}{|c|}{ Maternal reporting of the most beneficial feeding mode for infants } \\
\hline Formula feeding & $1 \cdot 1$ & 2 & $21 \cdot 7$ & 46 & $1 \cdot 0$ & & $1 \cdot 0$ & & \\
\hline No difference between formula and breast milk & $3 \cdot 2$ & 6 & 33.5 & 71 & 1.9 & $0 \cdot 3,10$ & $2 \cdot 4$ & $0 \cdot 4,13 \cdot 3$ & \\
\hline Breast-feeding & $95 \cdot 8$ & 181 & $44 \cdot 8$ & 95 & $43 \cdot 8$ & $10 \cdot 4,184$ & $39 \cdot 7$ & $8 \cdot 9,177$ & 0.000 \\
\hline
\end{tabular}

*Adjusted for maternal age and education, smoking status, parity and infant birth weight.

$\$ \neq 0$ denotes the reference category. 
Table 4 Factors influencing 'any' breast-feeding (AB) at 6 weeks in the Irish-national population, performed by binary logistic regression analysis

\begin{tabular}{|c|c|c|c|c|c|c|c|c|c|}
\hline \multirow[b]{2}{*}{ Factors } & \multicolumn{2}{|c|}{$\begin{array}{c}\mathrm{AB} \text { at } 6 \text { weeks } \\
(n 98)\end{array}$} & \multicolumn{2}{|c|}{$\begin{array}{l}\text { Non-AB at } 6 \\
\text { weeks }(n \text { 303) }\end{array}$} & \multicolumn{2}{|c|}{ Univariate } & \multicolumn{2}{|c|}{ Adjusted ${ }^{*}$} & \multirow[b]{2}{*}{$P$ value } \\
\hline & $\%$ & $n$ & $\%$ & $n$ & OR & $95 \% \mathrm{Cl}$ & OR & $95 \% \mathrm{Cl}$ & \\
\hline \multicolumn{10}{|l|}{ Maternal education } \\
\hline Primary and secondary & $13 \cdot 3$ & 13 & $48 \cdot 5$ & 147 & $1 \cdot 0+$ & & $1 \cdot 0$ & & \\
\hline Vocational/training course & $24 \cdot 5$ & 24 & $30 \cdot 0$ & 91 & $2 \cdot 9$ & $1 \cdot 4,6 \cdot 1$ & $2 \cdot 3$ & $1 \cdot 0,5 \cdot 1$ & \\
\hline Third level degree/postgraduate level & $62 \cdot 2$ & 61 & $21 \cdot 5$ & 65 & $10 \cdot 6$ & $5 \cdot 4,20 \cdot 6$ & $5 \cdot 7$ & $2 \cdot 7,12 \cdot 2$ & 0.000 \\
\hline \multicolumn{10}{|l|}{ Maternal age (years) } \\
\hline$\leq 24$ & $9 \cdot 2$ & 9 & $26 \cdot 7$ & 81 & $1 \cdot 0$ & & $1 \cdot 0$ & & \\
\hline $25-34$ & $54 \cdot 1$ & 53 & $61 \cdot 1$ & 185 & $2 \cdot 5$ & $1 \cdot 2,5 \cdot 4$ & $1 \cdot 1$ & $0 \cdot 4,3$ & \\
\hline$\geq 35$ & $36 \cdot 7$ & 36 & $12 \cdot 2$ & 37 & $8 \cdot 7$ & $3 \cdot 8,20$ & $4 \cdot 9$ & $1 \cdot 6,14 \cdot 4$ & 0.000 \\
\hline \multicolumn{10}{|l|}{ Parity } \\
\hline Multiparous & $43 \cdot 9$ & 43 & $53 \cdot 5$ & 162 & $1 \cdot 0$ & & $1 \cdot 0$ & & \\
\hline Primiparous & $56 \cdot 1$ & 55 & $46 \cdot 5$ & 141 & $1 \cdot 4$ & $0 \cdot 9,2 \cdot 3$ & $1 \cdot 9$ & $1,3 \cdot 4$ & 0.033 \\
\hline \multicolumn{10}{|l|}{ Gender } \\
\hline Female & $46 \cdot 9$ & 46 & $43 \cdot 6$ & 132 & $1 \cdot 0$ & & $1 \cdot 0$ & & \\
\hline Male & $53 \cdot 1$ & 52 & $56 \cdot 4$ & 171 & $0 \cdot 87$ & $0.5,1 \cdot 3$ & 0.24 & $0 \cdot 4,1 \cdot 2$ & $0 \cdot 24$ \\
\hline \multicolumn{10}{|l|}{$\begin{array}{l}\text { Timing of when mother made her } \\
\text { infant-feeding decision }\end{array}$} \\
\hline During the pregnancy & $27 \cdot 6$ & 27 & $43 \cdot 2$ & 131 & $1 \cdot 0$ & & $1 \cdot 0$ & & \\
\hline Pre-pregnancy & $72 \cdot 4$ & 71 & $56 \cdot 8$ & 172 & $2 \cdot 0$ & $1 \cdot 2,3 \cdot 2$ & $3 \cdot 5$ & $1 \cdot 9,6 \cdot 5$ & 0.000 \\
\hline \multicolumn{10}{|l|}{$\begin{array}{l}\text { Feeding mode encouraged by partner } \\
\text { postnatally } \ddagger\end{array}$} \\
\hline Did not encourage breast-feeding & $27 \cdot 8$ & 27 & $67 \cdot 3$ & 183 & $1 \cdot 0$ & & $1 \cdot 0$ & & \\
\hline Positively encouraged breast-feeding & $72 \cdot 2$ & 70 & $32 \cdot 7$ & 89 & $5 \cdot 3$ & $3 \cdot 1,8 \cdot 8$ & $4 \cdot 0$ & $2 \cdot 2,7 \cdot 3$ & 0.000 \\
\hline \multicolumn{10}{|l|}{ Mothers' antenatal feeding intention } \\
\hline No positive intention to breast-feed & $5 \cdot 1$ & 5 & 68 & 206 & $1 \cdot 0$ & & $1 \cdot 0$ & & \\
\hline Positive intention to breast-feed & $94 \cdot 9$ & 93 & 32 & 97 & $39 \cdot 5$ & 15,100 & $31 \cdot 7$ & $10 \cdot 5,95$ & $0 \cdot 000$ \\
\hline \multicolumn{10}{|l|}{$\begin{array}{l}\text { Mothers' antenatal attitude to } \\
\text { breast-feeding practice being }\end{array}$} \\
\hline Not natural & $32 \cdot 7$ & 32 & $61 \cdot 1$ & 185 & $1 \cdot 0$ & & $1 \cdot 0$ & & \\
\hline Natural & $67 \cdot 3$ & 66 & $38 \cdot 9$ & 118 & $3 \cdot 2$ & $1 \cdot 9,5 \cdot 2$ & $3 \cdot 7$ & $2,6 \cdot 8$ & 0.000 \\
\hline \multicolumn{10}{|l|}{$\begin{array}{l}\text { Employment status of mothers during } \\
\text { the first } 6 \text { months postpartum }\end{array}$} \\
\hline $\begin{array}{l}\text { Did not return to work outside the } \\
\text { home }\end{array}$ & $59 \cdot 2$ & 58 & 63 & 191 & $1 \cdot 0$ & & $1 \cdot 0$ & & \\
\hline Returned to work $\leq 18$ weeks & $19 \cdot 4$ & 19 & $19 \cdot 8$ & 60 & $1 \cdot 0$ & $0 \cdot 5,1 \cdot 8$ & 1.5 & $0 \cdot 7,3 \cdot 3$ & \\
\hline Returned to work $>18$ weeks & $21 \cdot 4$ & 21 & $17 \cdot 2$ & 52 & $1 \cdot 3$ & $0 \cdot 7,2 \cdot 3$ & $0 \cdot 9$ & $0 \cdot 4,1 \cdot 8$ & 0.441 \\
\hline
\end{tabular}

*Adjusted for maternal age, education, smoking status, parity, infant birth weight and parental social class.

+1.0 denotes the reference category.

$\ddagger n 369$ mothers reported that they had a partner who was actively involved in their lives.

between 2004 and 2006. Nonetheless, based on the differing breast-feeding rates between the non-Irish-nationals and Irish-nationals in the present study, our results suggest that a separate analysis of breast-feeding rates by mothers' nationality in future breast-feeding monitoring systems and NPS reports in Ireland may yield valuable information as regards national breast-feeding trends over time.

An extremely low level of compliance with the WHO (2001) recommendation was found in the present study, with only one Irish-national mother reported to be exclusively breast-feeding at 6 months. A similarly low exclusive breast-feeding rate of $<1 \%$ at 6 months was reported in an earlier national infant-feeding study ( $n$ $1195)^{(64)}$ indicating that there has been no prolongation of exclusive breast-feeding among Irish mothers over the last 20 years. The rate of exclusive breast-feeding at 6 months, however, appears low worldwide with rates of $6 \%$ and $4.7 \%$ reported in China ${ }^{(54)}$ and Italy, respectively $^{(65)}$. It is a further concern that mothers in the present study were reluctant to exclusively breast-feed to 16 weeks postpartum with rates in the Irish-national and nonIrish-national populations dropping to $7 \cdot 2 \%$ and $18 \cdot 4 \%$ respectively, at this time point.

A precipitous drop in the 'any' breast-feeding rate in the Irish-national mothers between each follow-up point in the present study was also highlighted. The highest drop in 'any' breast-feeding occurred during the hospital stay $(8.3 \%)$ and between hospital discharge and 4 weeks postpartum $(10 \cdot 3 \%)$ in the Irish-national population. Other investigators in Ireland have reported similar findings ${ }^{(40,59)}$. The fact that almost $40 \%$ of Irish-national mothers who initiated breast-feeding in the hospital had abandoned the practice by 4 weeks suggests that the interval from birth to 4 weeks is particularly sensitive to a change in the feeding decision and breast-feeding cessation. Although the two study populations experienced similar support from the health professionals in the hospital (2004-2006), few non-Irish-national mothers abandoned breast-feeding during the hospital stay. Taken 
together, our data suggest that a breast-feeding-supportive culture in the latter population exists and was likely to have contributed towards continued breast-feeding during the first 6 months.

It is a further possibility that the higher breast-feeding rates observed in the non-Irish-national population may be explained by the significantly greater proportion of married and/or stay-at-home mothers in this population, factors that are known to be positively associated with breast-feeding ${ }^{(66,67)}$; however, variability in breastfeeding rates by ethnic diversity has been reported by other investigators ${ }^{(68,69)}$. Data from Kelly and collegues ${ }^{(68)}$ in the UK ( $n$ 17 474) found that the highest breast-feeding rates from initiation to 3 months postpartum, after adjustment, were among the Black African, Black Caribbean and Asian, compared to White mothers. Similarly, foreignLatina mothers in the USA were more likely to initiate breast-feeding than USA-born Latina, or White nonHispanic mothers ${ }^{(69)}$. Furthermore, data from the present study show that partial rather than exclusive or predominant breast-feeding was a more common practice among non-Irish-national, compared to the Irish-national mothers throughout the study, a practice that contributed to the maintenance of their 'any' breast-feeding rates to 6 months. It is well established that culturally based feeding beliefs influence how mothers make decisions ${ }^{(70)}$; however, the context of maternal beliefs and decisions can also change in those who immigrate to a different culture and geographic region ${ }^{(71)}$. An examination of the effect of immigration to Ireland on the breastfeeding practices of the non-Irish-national population should thus be considered in future research.

The present study also sought to identify the factors that influence breast-feeding initiation and 'any' breastfeeding at 6 weeks in the Irish-national population. Similar to earlier international ${ }^{(31,72,73)}$ and regional Irish studies $^{(38,44)}$, our data show that sociodemographic variables, including maternal age, education level and parity, were consistent predictive factors in determining breastfeeding initiation and 'any' breast-feeding at 6 weeks. In particular, mothers who had a third level education were almost six times more likely to have been breast-feeding at 6 weeks $(P=0 \cdot 000)$ compared to those who had a primary or secondary educational attainment level. Although work return has been reported as a barrier to breast-feeding initiation and duration in other studies from the USA ${ }^{(74)}$ and $\mathrm{UK}^{(75)}$, no significant associations were observed between these variables in the present study.

There is little doubt from our data that a positive antenatal intention to breast-feed is one of the strongest and persistent independent predictors of breast-feeding initiation and 'any' breast-feeding at 6 weeks, a finding that agrees with other studies ${ }^{(76,77)}$. The importance of the antenatal period in determining breast-feeding success postpartum in the present study is further highlighted by the fact that mothers who made their decision to breastfeed pre-pregnancy were more likely to offer breast milk to their infants at 6 weeks. Our data suggest that in order to improve breast-feeding rates, the antenatal period should be targeted as being an effective time in which to concentrate efforts to promote breast-feeding. Moreover, exploring the concerns of parents who indicate ambivalence or resistance towards breast-feeding antenatally may be essential in addressing socio-cultural issues and misperceptions ${ }^{(78)}$.

Results from the present study also underscore the importance of positive encouragement from the partner and maternal grandmother to breast-feed on initiation and duration postpartum. Consistent with these associations, a wealth of evidence highlights the importance of social and emotional support from the partner ${ }^{(79,80)}$, family members and friends in promoting breast-feeding initiation and duration ${ }^{(81,82)}$. The provision of partner and grandmother-specific infant-feeding information and guidance during the ante- and postnatal period may prove to be an effective measure in the promotion of breast-feeding, across all socio-economic groups.

Other emerging themes from our data relate to the important role of positive maternal attitudes and perceptions of the acceptability of breast-feeding in public in determining breast-feeding rates. In another Irish study, confusion around the dual feeding/sexual role of the female breast has been shown to be associated with the embarrassment of breast-feeding, with the majority of participants reporting that they disapproved of the practice in public ${ }^{(83)}$. Moreover, maternal attitudes, compared to sociodemographic factors, have been suggested as better predictors of feeding choice ${ }^{(84)}$. Although national efforts to promote breast-feeding as a cultural norm continue, results from the present study highlight the perception among many mothers that breast-feeding is a social taboo and an embarrassing way to feed an infant. These data are further supported by mothers' principal reasons for choosing not to breast-feed in the present study, with the 'embarrassment issue' being a priority among almost a third of these mothers (31\%). Clearly, the cultural barrier towards breast-feeding appears to still prevail among mothers in Ireland, and if our breastfeeding rates are to ever improve, stronger motivations and creative campaigns that relate directly towards addressing the negative cultural perception of the practice need to be considered.

Positive features of the present study include the high follow-up response rates and the consistent and strict use of breast-feeding definitions. Several limitations of the work must also be considered. Firstly, the fact that mothers were recruited and lived within a similar geographical area may limit the generalisability of the data to the rest of Ireland. The fact that there was an underrepresentation of mothers recruited from public antenatal clinics $(51 \%)$, relative to the proportion that attend such clinics in the CWIUH (58\%), may also have influenced 
our results. Finally, long-term recall of breast-feeding data has been found to be inaccurate ${ }^{(85)}$ and it is possible that the maternal reporting of the feeding status of some infants at 4, 8, 12, 16 and 20 weeks, in particular, was influenced by maternal memory bias. Due to direct maternal reporting of the feeding status of infants at 6 weeks and 6 months, however, the accuracy of the feeding status at these time points can be assured.

\section{Conclusions}

Non-Irish-national, compared to Irish-national, mothers were significantly more likely to initiate and offer 'any' breast milk to their infants during the first 6 months postpartum. The WHO (2001) recommendation was adhered to by only one Irish-national mother. Based on our results, the antenatal period is an effective time for concentrating efforts to encourage women to breast-feed. Involving the partner and the maternal grandmother in ante and postnatal breast-feeding initiatives appears crucial to increase rates. Finally, mothers' perception of the social acceptability of breast-feeding in Ireland is strongly highlighted as an important determinant of both breastfeeding initiation and duration.

\section{Acknowledgements}

The present study was funded by the Dublin Institute of Technology, Dublin 8. The authors thank the 491 mothers who participated in the present study and acknowledge the cooperation of the midwives, obstetricians and administration staff in the CWIUH throughout the study. R.C.T., K.M.Y. and J.M.K. were responsible for the study design and the interpretation of the results (J.M.K. was the study coordinator/supervisor). R.C.T. was responsible for data collection, input and analysis, as well as the write-up of the draft manuscript. K.M.Y., J.M.K, M.S.-P. and M.J.W. contributed to the editing of the final manuscript. The authors declare no conflict of interest.

\section{References}

1. Kramer MS \& Kakuma R (2002) The Optimal Duration of Exclusive Breastfeeding: A Systematic Review. Geneva: WHO; available at http://www.who.int/nutrition/topics/optimal_ duration_of_exc_bfeeding_review_eng.pdf

2. Fewtrell MS (2004) The long-term benefits of having been breast-fed. Curr Paediatr 14, 97-103.

3. Heinig MJ \& Dewey KG (1997) Health effects of breastfeeding for mothers: a critical review. Nutr Res Rev 10, 35-56.

4. Baker JL, Gamborg M, Heitmann BL, Lissner L, Sorensen TI \& Rasmussen KM (2008) Breast-feeding reduces postpartum weight retention. Am J Clin Nutr 88, 1543-1551.

5. Villalpando S \& Lopez-Alarcon M (2000) Growth faltering is prevented by breast-feeding in under-privileged infants from Mexico City. J Nutr 130, 546-552.
6. Betran AP, de Onis M \& Lauer JA (2001) Ecological study of the effect of breastfeeding on infant mortality in Latin America. BMJ 323, 303-306.

7. Howie PW, Forsyth JS, Ogston SA, Clark A \& Florey CD (1990) Protective effect of breastfeeding against infection. BMJ 300, 11-16.

8. Wilson AC, Forsyth JS, Greene SA, Irvine L, Han C \& Howie PW (1998) Relation of infant diet to childhood health: seven year follow up of cohort of children in Dundee infant feeding study. BMJ 316, 21-25.

9. Oddy WH, Sly PD, de Klerk NH, Landau LI, Kendell GI, Holt PG \& Stanley FJ (2003) Breastfeeding and respiratory morbidity in infancy: a birth cohort study. Arch Dis Child 88, 224-228.

10. American Academy of Pediatrics (2005) Breastfeeding and use of human milk policy statement. Pediatrics 115, 496-506.

11. European Society for Paediatric Gastroenterology, Hepatology and Nutrition (2008) Complementary feeding, a commentary by the ESPGHAN Committee on Nutrition: medical position paper. J Pediatr Gastroenterol Nutr 46, 99-110.

12. von Kries R, Koletzko B, Sauerwald T, von Mutius E, Barnert D, Grunert V \& von Voss H (1999) Breastfeeding and obesity: cross-sectional study. BMJ 319, 147-150.

13. Harder T, Bergmann R, Kallischnigg G \& Plagemann A (2005) Duration of breastfeeding and risk of overweight: a meta-analysis. Am J Epidemiol 162, 397-403.

14. Gillman M (2002) Breastfeeding and obesity. J Pediatr 141 , 749-750.

15. Singhal A \& Lanigan J (2007) Breastfeeding, early growth and later obesity. Obes $\operatorname{Rev} \mathbf{8}, 51-54$.

16. Stettler N (2007) Nature and strength of epidemiological evidence for origins of childhood and adulthood obesity in the first year of life. Int J Obes (Lond) 31, 1035-1043.

17. Southern Area Health Service Executive (2005) Our children, their future, why weight? Survey series and literature review on childhood obesity. Cork: Department of Public Health, Health Service Executive - Southern Area.

18. O'Neill JL, McCarthy SN, Burke SJ, Hannon EM, Kiely M, Flynn A, Flynn MA \& Gibney MJ (2007) Prevalence of overweight and obesity in Irish school children, using four different definitions. Eur J Clin Nutr 61, 743-751.

19. Flegal KM, Carroll MD, Ogden CL \& Johnson CL (2002) Prevalence and trends in obesity among US adults, 1999-2000. JAMA 288, 1723-1727.

20. World Health Organization (2003) Obesity and Overweight: Global Strategy on Diet, Physical Activity and Health. Geneva: WHO; available at http://www.who.int/ dietphysicalactivity/publications/facts/obesity/en/

21. World Health Organization (2001) Global Strategy on Infant and Young Child Feeding. The Optimal Duration of Exclusive Breastfeeding. The 54th World Health Assembly. Geneva: WHO; available at http://ftp.who.int/gb/archive/ pdf_files/WHA54/ea54id4.pdf

22. Department of Health and Children (2003) Policy Change in Breastfeeding Guidelines. Dublin: Health promotion Unit, Department of Health and Children. http://www. dohc.ie/press/releases/2003/20030805.html

23. World Health Organization (2009) Global Data Bank on Breastfeeding and Complementary Feeding. Geneva: WHO; available at http://www.who.int/research/iycf/bfcf/ bfcf.asp?menu $=21 \& \mathrm{cID}=$ hnd \&iID $=\& y I D=\& o k=$ true

24. Department of Health and Children (1994) National Breastfeeding Policy for Ireland. Dublin: Department of Health and Children.

25. Freeman V, van't Hof M \& Haschke F (2000) Patterns of milk and food intake in infants from birth to age 36 months: the Euro Growth Study. J Pediatr Gastroenterol Nutr 31, S76-S85.

26. Cattaneo A, Yngve A, Koletzko B \& Guzman LR (2005) Protection, promotion and support of breast-feeding in Europe: current situation. Public Health Nutr 8, 39-46. 
27. Tarrant RC \& Kearney JM (2008) Review of breastfeeding practices in Ireland. Proc Nutr Soc 67, 371-380.

28. The Economic, Social and Research Institute and Department of Health and Children (2006) Report on the National Perinatal Statistics 2001-2005. http://www.esri.ie/health_ information/latest_hipe_nprs_reports/ (accessed January 2009).

29. Lanting C, Van Wouwe J \& Reijneveld S (2005) Infant milk feeding practices in the Netherlands and associated factors. Acta Paediatr 94, 935-942.

30. Li R, Darling N, Maurice E, Barker L \& Grummer-Strawn LM (2005) Breastfeeding rates in the United States by the characteristics of the child, mother or family: the 2002 National Immunization Survey. Pediatrics 115, 31-37.

31. Kelly Y \& Watt R (2005) Breast-feeding initiation and exclusive duration at 6 months by social class: results from the Millennium Cohort Study. Public Health Nutr 8, 417-421.

32. Losch M, Dungy CI, Russell D \& Dusdieker LB (1995) Impact of attitudes on maternal decisions regarding infant feeding. J Pediatr 126, 507-514.

33. Yngve A \& Sjostrom M (2001) Breastfeeding determinants and a suggested framework for action in Europe. Public Health Nutr 4, 729-739.

34. Food Safety Authority of Ireland (1999) Recommendations for a National Infant Feeding Policy. Dublin: Food Safety Authority of Ireland.

35. Department of Health and Children (2005) Breastfeeding in Ireland: A Five-Year Strategic Action Plan. Dublin: Department of Health and Children.

36. Central Statistics Office Ireland (2006) Population classified by religion and nationality 2006. http://www.cso.ie/statistics/ popnclassbyreligionandnationality2006.htm (accessed January 2009).

37. Mid-Western Health Board Survey (1997) Infant Feeding Survey. Limerick: Mid-Western Health Board, Department of Public Health.

38. Ward M, Sheridan A, Howell F, Hegarty J \& O'Farrell A (2004) Infant feeding: factors affecting initiation, exclusivity and duration. Ir Med J 97, 197-199.

39. Sayers G, Thornton L, Corcoran R \& Burke M (1995) Influences on breastfeeding initiation and duration. Ir J Med Sci 164, 281-284.

40. Howell F, Bedford D, O'Keefe B \& Corcoran R (1996) Breastfeeding in the Health Board Region. Navan: North Eastern Health Board, Department of Public Health Medicine.

41. Loh NR, Kelleher CC, Long S \& Loftus BG (1997) Can we increase breastfeeding rates? Ir Med J 90, 100-101.

42. Cattaneo A, Davanzo R \& Ronfani L (2000) Are data on the prevalence and duration of breastfeeding reliable? The case study of Italy. Acta Paediatr 89, 88-93.

43. O'Herlihy BP (1978) Breastfeeding: incidence and influences. Ir Med J 71, 404-407.

44. Hurley M \& Fogarty J (1992) A Study of Infant Feeding Practices in Ireland. Dublin: Eastern Health Board.

45. Meyerink RO \& Marquis GS (2002) Breastfeeding initiation and duration among low-income women in Alabama: the importance of personal and familial experiences in making infant-feeding choices. J Hum Lact 18, 38-45.

46. Synnott K \& Bogue J (2004) An Exploratory Study of the Attitudes of German, Italian, Scottish and Swedish Parents of Young Infants to Infant Diet, Health and Allergies. Agribusiness Discussion Paper no. 41. Cork: Department of Food, Business and Development, University College Cork.

47. Hamlyn B, Brooker S, Oleinikova K \& Wands S (2002) UK Infant Feeding 2000. London: The Stationery Office.

48. Galtry J (2003) The impact on breastfeeding of labour market policy and practice in Ireland, Sweden and the USA. Soc Sci Med 57, 167-177.

49. Bakoula C, Veltsista A, Prezerakou A, Moustaki M, Fretzavas A \& Nicolaidou P (2007) Working mothers breastfeed babies more than housewives. Acta Paediatr 96, 510-515.

50. World Health Organization (1991) Indicators for Assessing Breastfeeding Practices, Division of Child Health and Development (WHO/CDD/SER/91). Geneva: WHO.

51. World Health Organization/UNICEF (1993) WHO Breastfeeding Counselling: A Training Course. Geneva: WHO.

52. Lande B, Anderson LF, Baerug A, Trygg KU, Lund-Larsen K, Veierod MB \& Bjorneboe GE (2003) Infant feeding practices and associated factors in the first six months of life: the Norwegian infant nutrition survey. Acta Paediatr 92, 152-161.

53. Brekke H, Ludvigsson J, van Odijk J \& Ludvigsson J (2005) Breastfeeding and introduction of solid foods in Swedish infants: the All Babies in Southeast Sweden study. Br J Nutr 94, 377-382.

54. Xu F, Binns C, Wu J, Yihan R, Zhao Y \& Lee A (2007) Infant feeding practices in Xinjiang Uygur autonomous region, People's Republic of China. Public Health Nutr 10, 198-202.

55. Office of Population Census and Surveys (1991) Standard Occupational Classification. vol. 3: Social Classifications and Coding Methodology. London: Her Majesty's Stationery Office.

56. Central Statistics Office Census (1996) vol. 7: Occupations. Dublin: Central Statistics Office.

57. Gilmore M, O'Driscoll D \& Murphy H (1978) A pilot survey of an attempt to promote breastfeeding. Ir J Med Sci 148, 272-275.

58. McSweeney M (1986) National Survey of Infant Feeding Practices. Dublin: Health Education Bureau.

59. Twomey A, Kiberd B, Matthews T \& O'Regan M (2000) Feeding infants: an investment in the future. Ir Med J 93, 248-250.

60. Bolling K, Grant C, Hamlyn B \& Thornton A (2007) UK Infant Feeding Survey 2005. London: The Stationery Office.

61. Chandrashekhar TS, Joshi HS, Binu VS, Shankar PR, Rana MS \& Ramachandran U (2007) Breast-feeding initiation and determinants of exclusive breast-feeding: a questionnaire survey in an urban population of western Nepal. Pub Health Nutr 10, 192-197.

62. Fitzpatrick CC, Fitzpatrick PE \& Darling MR (1994) Factors associated with the decision to breast-feed among Irish women. Ir Med J 87, 145-146.

63. Lowry M \& Lillis DF (1993) Infant feeding practices. Ir MedJ 86, 13-14.

64. McSweeney M \& Kevany J (1982) Infant Feeding Practices in Ireland: National Survey. Dublin: Health Education Bureau.

65. Giovannini M, Riva E, Banderali G, Scanglioni S, Veehof SH, Sala M, Radaelli G \& Agostoni C (2004) Feeding practices of infants through the first year of life in Italy. Acta Paediatr 93, 492-497.

66. Callen J \& Pinelli J (2004) Incidence and duration of breastfeeding for term infants in Canada, United States, Europe, and Australia: a literature review. Birth 31, 285-292.

67. Taylor JS, Risica PM, Geller L, Kirtania U \& Cabral HJ (2006) Duration of breastfeeding among first time mothers in the United States: results of a national survey. Acta Paediatr 95, 980-984.

68. Kelly Y, Watt R \& Nazroo J (2006) Racial/ethnic differences in breastfeeding initiation and continuation in the United Kingdom and comparison with findings in the United States. Pediatrics 118, 1428-1435.

69. Heck K, Braveman P, Cubbin C, Chavez GF \& Kiely JL (2006) Socioeconomic status and breastfeeding initiation among Californian mothers. Public Health Rep 121, 51-59.

70. Itina SM (1997) Characteristics of traditional birth attendants and their beliefs and practices in the Offot Clan, Nigeria. Bull World Health Organ 75, 563-567.

71. Kannan S, Carruth B \& Skinner J (1999) Infant feeding practices of Anglo American and Asian Indian American mothers. J Am Coll Nutr 18, 279-286. 
72. Grjibovski AM, Yngve A, Bygren LO \& Sjostrom M (2005) Socio-demographic determinants of initiation and duration of breastfeeding in northwest Russia. Acta Paediatr 94, 588-594.

73. Hendricks K, Briefel R, Novak T \& Ziegler P (2006) Maternal and child characteristics associated with infant and toddler feeding practices. J Am Diet Assoc 106, Suppl. 1, S135-S148.

74. Arora S, McJunkin C, Wehrer J \& Kuhn P (2000) Major factors influencing breastfeeding rates: mother's perception of father's attitude and milk supply. Pediatrics 106, 1-5.

75. Noble S; the ALSPAC Study Team (2001) Maternal employment and the initiation of breastfeeding. Acta Paediatr 90, 423-428.

76. Chye J, Zain Z, Lim W \& Lim CT (1997) Breastfeeding at 6 weeks and predictive factors. J Trop Pediatr 43, 287-292.

77. Donath SM \& Amir LH; the ALSPAC Study Team (2003) Relationship between prenatal infant feeding intention and initiation and duration of breastfeeding: a cohort study. Acta Pediatr 92, 352-356.

78. Wilhelm SL, Stepans MB, Hertzog M, Rodehorst TK \& Gardner P (2006) Motivational interviewing to promote sustained breastfeeding. J Obstet Gynecol Neonatal Nurs 35, 340-348.
79. Ingram J, Johnson D \& Greenwood R (2002) Breastfeeding in Bristol: teaching good positioning, and support from fathers and families. Midwifery 18, 87-101.

80. Okon M (2004) Health promotion: partners' perceptions of breastfeeding. Br J Midwifery 12, 387-393.

81. Cernadas JMC, Noceda G, Barrera L, Martinez AM \& Garsd A (2003) Maternal and perinatal factors influencing duration of exclusive breastfeeding in the first 6 months of life. J Hum Lact 19, 136-144.

82. Kong S \& Lee D (2004) Factors influencing decision to breastfeed. J Adv Nurs 46, 369-379.

83. Connolly C, Kelleher CC, Becker G, Friel S \& Gabhainn SN (1998) Attitudes of young men and women to breastfeeding. Ir Med J 91, 88-90.

84. Scott JA, Shaker I \& Reid M (2004) Parental attitudes toward breastfeeding: their association with feeding outcome at hospital discharge. Birth 31, 125-131.

85. Bland RM, Rollins NC, Solarsh G, Van den Broeck J \& Coovadia HM; Child Health Group (2003) Maternal recall of exclusive breastfeeding duration. Arch Dis Child 88, 778-783. 